\title{
The Economic Order Decision with Continuous Dynamic Pricing and Batch Supply
}

Citation for published version (APA):

van den Berg, A., Herings, P. J-J., \& Peters, H. (2017). The Economic Order Decision with Continuous Dynamic Pricing and Batch Supply. Operations Research Letters, 45(4), 371-376.

https://doi.org/10.1016/j.orl.2017.05.007

Document status and date:

Published: 01/07/2017

DOI:

10.1016/j.orl.2017.05.007

Document Version:

Publisher's PDF, also known as Version of record

Document license:

Taverne

Please check the document version of this publication:

- A submitted manuscript is the version of the article upon submission and before peer-review. There can be important differences between the submitted version and the official published version of record.

People interested in the research are advised to contact the author for the final version of the publication, or visit the DOI to the publisher's website.

- The final author version and the galley proof are versions of the publication after peer review.

- The final published version features the final layout of the paper including the volume, issue and page numbers.

Link to publication

\footnotetext{
General rights rights.

- You may freely distribute the URL identifying the publication in the public portal. please follow below link for the End User Agreement:

www.umlib.nl/taverne-license

Take down policy

If you believe that this document breaches copyright please contact us at:

repository@maastrichtuniversity.nl

providing details and we will investigate your claim.
}

Copyright and moral rights for the publications made accessible in the public portal are retained by the authors and/or other copyright owners and it is a condition of accessing publications that users recognise and abide by the legal requirements associated with these

- Users may download and print one copy of any publication from the public portal for the purpose of private study or research.

- You may not further distribute the material or use it for any profit-making activity or commercial gain

If the publication is distributed under the terms of Article $25 \mathrm{fa}$ of the Dutch Copyright Act, indicated by the "Taverne" license above, 


\title{
The economic order decision with continuous dynamic pricing and batch supply
}

\author{
Anita van den Berg ${ }^{a}$, P. Jean-Jacques Herings ${ }^{b, *}$, Hans Peters ${ }^{c}$ \\ a Capgemini Consulting, Reykjavikplein 1, 3543 KA, Utrecht, The Netherlands \\ b Department of Economics, Maastricht University, P.O. Box 616, 6200 MD, Maastricht, The Netherlands \\ c Department of Quantitative Economics, Maastricht University, P.O. Box 616, 6200 MD, Maastricht, The Netherlands
}

\section{A R T I C L E I N F O}

\section{Article history:}

Received 7 January 2016

Received in revised form 24 May 2017

Accepted 25 May 2017

Available online 2 June 2017

\section{Keywords:}

Dynamic pricing

Economic order decision

Inventory

\begin{abstract}
A B S T R A C T
In an infinite horizon inventory and sales model, we show that the seller's unique strategy exhibits increasing prices under general conditions on the revenue function. An increasing discount rate leads to an increase of the time interval between order times, but an increase in batch size has an ambiguous effect.
\end{abstract}

(c) 2017 Elsevier B.V. All rights reserved.

\section{Introduction}

A seller offers a single product to customers over infinite time, and these customers buy the product according to a deterministic demand function. The seller uses dynamic pricing to maximize his time-discounted profits. The seller is a retailer who can only acquire the good in large bulks, at a fixed cost for every new batch. Our model considers inventory holding costs implicitly by maximizing time-discounted profits, which captures the opportunity cost of the capital when accounting for the inventory holding cost. A typical example is an airline company which plans flight schedules ahead over a certain stretch of time and typically offers tickets at changing, usually increasing, prices.

For overviews of the literature on dynamic pricing in the presence of inventory considerations, see [2,9], and [7]. With only few exceptions, mentioned below, this literature maximizes average profits over a fixed time horizon and assumes that any quantity can be ordered.

A strategy of the seller consists of a specification of order times and sales prices at each point in time. Under concavity of the revenue function, the seller's optimal strategy turns out to be stationary and unique. It is characterized by the time that elapses between any two order moments and an optimal path of increasing prices or, equivalently, increasing prices.

\footnotetext{
* Corresponding author.

E-mail addresses: ahjvdberg@hotmail.com (A. van den Berg), p.herings@maastrichtuniversity.nl (P.J.J. Herings), h.peters@maastrichtuniversity.nl (H. Peters).
}

In a comparative statics analysis, we show that the time between two order moments increases with batch cost, a result that confirms intuition. In the case of linear demand, we show that the time between two order moments also increases with the discount rate, but it is not clear whether this is the case for more general demand functions. As to the effect of batch size on the time between order moments, intuition suggests a positive effect. However, even for the case with linear demand functions, we show that it can be both positive and negative.

The works that are closest to our approach are on the one hand [18] and on the other hand [8] and [12]. The first paper considers the maximization of average profits over a fixed time horizon rather than discounted profits over an infinite time horizon. Another important difference with [18] is that we assume the good is ordered in batches of a fixed size. In that respect our approach is similar to [8] and [12], among the few papers in the literature that also consider this case. Contrary to our model of continuous price setting, these two papers consider the case where prices are set at the beginning of each period. Other related works, following the seminal contribution [14], are [17] and [10]. Extensions to multiple interacting players are considered in [15] and [16]. This literature also maximizes discounted profits using dynamic pricing, but deals with a fixed planning horizon and firms which operate under a convex increasing production cost function and choosing a production rate.

Further papers in the literature also assume deterministic demand functions, but consider discrete time models. A notable example is [13] which considers the case with multiple items and demand functions exhibiting seasonality. In [4], the effects of costly 
price adjustment are analyzed, allowing for different costs for price increases versus price decreases.

Still other papers have studied models where demand is stochastic, see [5,6,11], and [3].

In Section 2, we introduce the model. Section 3 provides the optimal sales strategy. Section 4.1 provides the general sensitivity analysis with respect to the parameters of the model, and Section 4.2 analyzes the case of linear demand. Section 5 concludes.

\section{The model}

A manufacturer delivers a non-perishable good in batches of size $S>0$ for a price $K>0$. The price $K$ is the total cost for the seller. The seller's inventory level can never become negative, that is, backlogging is not allowed. He can choose when to order new stock and how much he is willing to sell from the stock at every moment in time. Newly ordered stock is delivered instantly. Time is continuous and the time horizon is infinite.

Revenue streams and costs are discounted at a rate of $r>0$. We assume that $r$ is also equal to his opportunity cost of capital and therefore include inventory holding costs related to the opportunity cost of capital invested in inventories. Other holding costs like the costs of decay and costs related to space and handling of the product should be incorporated explicitly when deemed important. This is a possible extension of the current model.

The non-negative quantity $q(t)$ is the amount of the good the seller decides to supply at time $t$. The resulting function $q$ is assumed to belong to $Q$, the set functions that are piecewise continuous on any finite interval of $[0, \infty)$ and do not have removable discontinuities.

The instantaneous revenue for selling a quantity is given by the continuous function $R$ on $[0, \infty)$. We assume that $R$ is positive on an interval $(0, A)$, is zero on $\{0\} \cup[A, \infty)$, is twice continuously differentiable on $[0, A)$, has a unique maximum at $q^{\mathrm{m}}$ such that $0<q^{\mathrm{m}}<A$, and is strictly concave on $[0, A]$. Notice that the twice differentiability of $R$ at 0 implies that $R^{\prime}(0)$ is finite.

Let $X(t)$ be the inventory level of the seller at time $t \geqslant 0$, and let $T_{0}, T_{1}, \ldots$ with $T_{0}=0$ be the order moments. Between order moments, stock decreases with rate $q(t)$, and at each order moment it increases with $S$. A strategy is a tuple $\sigma=\left(q, T_{1}, \ldots\right)$ such that $q \in Q, T_{1}, \ldots \in \mathbb{R}$ with $0<T_{1}<\ldots$, and such that $X(t) \geqslant 0$ for all $t \geq 0$. By $\mathcal{S}$, we denote the set of all strategies. The seller therefore faces the following optimal control problem.

$\max _{\left(q, T_{1}, \ldots\right) \in \mathcal{S}} \sum_{i=0}^{\infty}\left(\int_{T_{i}}^{T_{i+1}} e^{-r t} R(q(t)) d t-e^{-r T_{i}} K\right)$

subject to

$X(0)=S, \dot{X}(t)=-q(t)$; for all $i \geqslant 1, X\left(T_{i}\right)=\lim _{t \uparrow T_{i}} X(t)+S$.

Observe that $X(t)$ has discontinuities at the points $T_{1}, T_{2}$, etc. At these points, $\dot{X}(t)$ is interpreted as the right derivative.

We assume that the seller can make a positive profit on each batch, that is, $K$ is smaller than the maximum discounted revenue that the seller can receive for selling a single batch of size $S$.

\section{The optimal order path}

We start with some useful observations. First, in an optimal strategy the seller will never run out of stock, so $X(t)>0$ for all $t \geqslant 0$, since otherwise he could simply shift part of his strategy to the moment where he first ran out of stock, and increase his profits due to discounting, contradicting optimality. Second, in an optimal strategy the seller will never order before he runs out of stock, since in such a case he could increase profits by postponing reordering until he runs out of stock, thereby decreasing costs, again due to discounting. Third, in an optimal strategy we have $q(t) \leqslant q^{\mathrm{m}}$ for all $t \geqslant 0$, since otherwise decreasing the offered quantity to $q^{\mathrm{m}}$ both increases instantaneous profit and decreases the cost of ordering new stock due to discounting - since sales speed is reduced, reordering is postponed.

We summarize these observations in the following lemma.

Lemma 3.1. Let $\sigma=\left(q, T_{1}, \ldots\right) \in \mathcal{S}$ be an optimal strategy for problem (1). Then, for all $t \geqslant 0$ and $i \geqslant 1$, we have $X(t)>0$, $\lim _{t \uparrow T_{i}} X(t)=0$, and $q(t) \leqslant q^{\mathrm{m}}$.

As a step towards solving (1), we first determine the optimal strategy for selling a batch $S$ in a fixed time interval $[0, T]$. As in Lemma 3.1, it is not hard to see that we may assume $T \geqslant T^{\mathrm{m}}=$ $S / q^{\mathrm{m}}$.

Let $Q^{T}$ be the set of non-negative piecewise continuous functions without removable discontinuities with domain $[0, T]$. The optimal control problem to solve for the case without reordering is

$\max _{q \in Q^{T}} \int_{0}^{T} e^{-r t} R(q(t)) d t$

subject to

$X(0)=S, X(T)=0, \dot{X}(t)=-q(t)$ for all $t \in[0, T]$.

Note that we can set $X(T)=0$ since we are considering the case without reordering.

Problem (2) can be handled by Pontryagin's maximum principle. See [1] for the (simple) derivation of the following proposition.

Proposition 3.2. (a) Problem (2) has a solution. If $q^{*} \in Q^{T}$ is such a solution, then $q^{*}$ is continuous on $[0, T]$ and there is $c^{*} \geqslant 0$ and $t^{*} \in\left[T^{\mathrm{m}}, T\right]$ such that

$R^{\prime}\left(q^{*}(t)\right)=c^{*} e^{r t}$ for $t \in\left[0, t^{*}\right], q^{*}(t)=0$ for $t \in\left(t^{*}, T\right]$,

and

$\int_{0}^{t^{*}} q^{*}(t) d t=S$

(b) The triple $\left(q^{*}, c^{*}, t^{*}\right)$ in (a) is uniquely determined by (3) and (4).

It can be seen from this proposition, in particular from part (b), that, if $\left(q^{*}, c^{*}, t^{*}\right)$ is the optimal solution for a given $T$ and if either $t^{*}<T$, or $t^{*}=T$ and $q^{*}\left(t^{*}\right)=0$, then $\left(q^{*}, c^{*}, t^{*}\right)$ is also the optimal solution for any $T^{\prime}$ with $T^{\prime} \geqslant t^{*}$.

We now denote the optimal triple for $T$ by $\left(q^{T}, c^{T}, t^{T}\right)$. See [1] for the (simple) proof of the following lemma.

Lemma 3.3. There is a $T>0$ such that $t^{T}<T$.

By Lemma 3.3 and the observation following Proposition 3.2 there is a $\widehat{T}>T^{\mathrm{m}}$ such that $t^{T}=T$ for all $T \in\left[T^{\mathrm{m}}, \widehat{T}\right]$ and $t^{T}=\widehat{T}$ for all $T \geqslant \widehat{T}$. In view of Lemma 3.1, we may therefore restrict attention to $T \in\left[T^{\mathrm{m}}, \widehat{T}\right]$ as the time between two order moments in problem (1).

Let $w^{*}$ denote the maximum discounted revenue that the seller can receive for selling a single batch of size $S$. Clearly, the selling time that the seller needs to achieve this maximum is at most $\widehat{T}$. On the other hand, it cannot be smaller than $\widehat{T}$ since then the optimal solution of problem (2) for $T=\widehat{T}$ would not be unique, contradicting Proposition 3.2. Thus, we have the following result.

Lemma 3.4. $w^{*}=\int_{0}^{\widehat{T}} e^{-r t} R\left(q^{\widehat{T}}(t)\right) d t$.

Our assumption that the seller can make a positive profit on each batch is therefore equivalent to $K<w^{*}$.

We now turn to the seller's original problem (1). We first restrict our analysis to so-called stationary strategies. A strategy $\sigma=$ 
$\left(q, T_{1}, \ldots\right)$ is stationary if $T_{i}=i T_{1}$ for all $i \geqslant 2$ and $q(t)=q(t$ $\left.\bmod T_{1}\right)$ for all $t \geqslant 0$. We denote such a strategy by the pair $(q, T)$, where $T=T_{1}$. Since we may restrict attention to $T \in\left[T^{\mathrm{m}}, T\right]$, we consider stationary strategies in $Q \times\left[T^{\mathrm{m}}, \widehat{T}\right]$.

For $T \in\left[T^{\mathrm{m}}, \widehat{T}\right]$, the revenue of the seller within a single sales period starting at time 0 is equal to

$V(T)=\int_{0}^{T} e^{-r t} R\left(q^{T}(t)\right) d t$.

Since $V$ is a continuous function, also total profit

$\Pi(T)=\sum_{i=0}^{\infty} e^{-r i T}(V(T)-K)=\frac{V(T)-K}{1-e^{-r T}}$

is a continuous function on the interval $\left[T^{\mathrm{m}}, \widehat{T}\right]$ and therefore attains a maximum, say at $T^{*}$.

The following lemma determines $T^{*}$ as the solution of an equation.

Lemma 3.5. The argument $T^{*}$ maximizing $\Pi:\left[T^{\mathrm{m}}, \widehat{T}\right] \rightarrow \mathbb{R}$ is unique and belongs to $\left(T^{\mathrm{m}}, \widehat{T}\right)$. In particular, $T^{*}$ is the solution of the following equation in $T$ :

$$
\begin{aligned}
& \left(e^{r T}-1\right)\left(e^{-r T} R\left(q^{T}(T)\right)-c^{T} q^{T}(T)\right) \\
& \quad+r\left(K-\int_{0}^{T} e^{-r t} R\left(q^{T}(t)\right) d t\right)=0 .
\end{aligned}
$$

Proof. We first compute the first and second derivatives of $V$ with respect to $T$, denoted by $V^{\prime}$ and $V^{\prime \prime}$, respectively. Differentiating the identity $\int_{0}^{T} q^{T}(t) d t=S$ on both sides with respect to $T$, we obtain

$q^{T}(T)+\int_{0}^{T} \frac{\partial q^{T}(t)}{\partial T} d t=0$.

Now,

$$
\begin{aligned}
V^{\prime}(T) & =e^{-r T} R\left(q^{T}(T)\right)+\int_{0}^{T} e^{-r t} R^{\prime}\left(q^{T}(t)\right) \frac{\partial q^{T}(t)}{\partial T} d t \\
& =e^{-r T} R\left(q^{T}(T)\right)+\int_{0}^{T} c^{T} \frac{\partial q^{T}(t)}{\partial T} d t \\
& =e^{-r T} R\left(q^{T}(T)\right)-c^{T} q^{T}(T),
\end{aligned}
$$

where the second equality follows from (3) and the third equality from (6). Differentiating (7) once again we obtain

$$
\begin{aligned}
V^{\prime \prime}(T)= & -r e^{-r T} R\left(q^{T}(T)\right)+e^{-r T} R^{\prime}\left(q^{T}(T)\right) \\
& \times \frac{\partial q^{T}(T)}{\partial T}-\frac{\partial c^{T}}{\partial T} q^{T}(T)-c^{T} \frac{\partial q^{T}(T)}{\partial T} \\
= & -r e^{-r T} R\left(q^{T}(T)\right)-\frac{\partial c^{T}}{\partial T} q^{T}(T) .
\end{aligned}
$$

Combining (7), (8), and the facts that $\partial q^{T}(t) / \partial T \leqslant 0$ and $\partial c^{T} / \partial T \geqslant$ 0 for all $T \geqslant 0$ and $t \in[0, T]$ (see [1] for a proof), we obtain

$V^{\prime \prime}(T)+r V^{\prime}(T)=-\frac{\partial c^{T}}{\partial T} q^{T}(T)-r c^{T} q^{T}(T) \leqslant 0$,

which will be useful at several places below.

The first derivative $\Pi^{\prime}$ of $\Pi$ with respect to $T$ is

$\Pi^{\prime}(T)=\frac{V^{\prime}(T)\left(1-e^{-r T}\right)-(V(T)-K) r e^{-r T}}{\left(1-e^{-r T}\right)^{2}}$.

If $T$ is a stationary point of $\Pi$, i.e., $\Pi^{\prime}(T)=0$, then (10) implies

$r(V(T)-K)=V^{\prime}(T)\left(e^{r T}-1\right)$.

Now, (5) follows from (11) and (7).
We observe that Eq. (5) evaluated at $T=T^{\mathrm{m}}$ is equal to

$$
\begin{aligned}
& \left(e^{r T^{\mathrm{m}}}-1\right)\left(e^{-r T^{\mathrm{m}}} R\left(q^{\mathrm{m}}\right)\right)+r\left(K-\int_{0}^{T^{\mathrm{m}}} e^{-r t} R\left(q^{\mathrm{m}}\right) d t\right) \\
& \quad=R\left(q^{\mathrm{m}}\right)-e^{-r T^{\mathrm{m}}} R\left(q^{\mathrm{m}}\right)+r K-R\left(q^{\mathrm{m}}\right)+e^{-r T^{\mathrm{m}}} R\left(q^{\mathrm{m}}\right)=r K>0
\end{aligned}
$$

and Eq. (5) evaluated at $T=\widehat{T}$ equals

$r\left(K-\int_{0}^{\widehat{T}} e^{-r t} R\left(q^{\widehat{T}}(t)\right) d t\right)=r\left(K-w^{*}\right)<0$.

It follows that a stationary point $T^{*}$ belongs to the open interval $\left(T^{\mathrm{m}}, \widehat{T}\right)$, hence $q^{T^{*}}\left(T^{*}\right)>0$ and therefore (9) holds with strict inequality at a stationary point,

$V^{\prime \prime}\left(T^{*}\right)+r V^{\prime}\left(T^{*}\right)<0$.

Differentiating (10) once again, we obtain after some simplifications:

$$
\begin{aligned}
\left(1-e^{-r T}\right)^{3} \Pi^{\prime \prime}(T)= & V^{\prime \prime}(T)\left(1-2 e^{-r T}+e^{-2 r T}\right) \\
& +V^{\prime}(T)\left(2 r e^{-2 r T}-2 r e^{-r T}\right) \\
& +V(T)\left(r^{2} e^{-r T}+r^{2} e^{-2 r T}\right) \\
& +K\left(-r^{2} e^{-r T}-r^{2} e^{-2 r T}\right) .
\end{aligned}
$$

At a stationary point, using (11), the sum of the terms in (14) can be written as $V^{\prime}(T) r\left(1-e^{-2 r T}\right)$. Combining this with (13), we obtain

$\left(1-e^{-r T}\right)^{3} \Pi^{\prime \prime}(T)=\left(V^{\prime \prime}(T)+r V^{\prime}(T)\right)\left(1-2 e^{-r T}+e^{-2 r T}\right)$.

Since $1-2 e^{-r T}+e^{-2 r T}=\left(1-e^{-r T}\right)^{2}>0$ for $T>0$, and (9) holds with strict inequality at a stationary point, the right-hand side of (15) is negative. This implies that the maximizer $T^{*}$ must be unique.

It is now straightforward that the unique optimal stationary strategy found in Lemma 3.5 is also the unique optimal strategy in $\mathcal{S}$, due to the stationary character of optimization problem (1). Thus, we have

Theorem 3.6. Problem (1) has a unique optimal strategy, namely the stationary strategy $\left(q^{*}, T^{*}\right)$ with $T^{*} \in\left(T^{\mathrm{m}}, \widehat{T}\right)$ satisfying (5) and $q^{*}=q^{T^{*}}$.

Observe that Theorem 3.6 (or Lemma 3.5) implies that the optimal quantity sold is always strictly in between 0 and the static monopoly quantity $q^{m}$.

\section{Sensitivity analysis of the optimal order time}

In this section, we investigate how $T^{*}$ changes if the parameters of the model change, namely the batch cost $K$, the discount rate $r$, and the batch size $S$. We start with a general analysis and then consider the special case of a linear demand function.

\subsection{General analysis}

We denote the first and second order partial derivatives with respect to $T, K, r$, and $S$ by subscripts, and often omit arguments when no confusion is likely to arise.

Proposition 4.1. Let $\left(q^{*}, T^{*}\right)$ be the optimal strategy of (1). Then,

(a) $T_{K}^{*}>0$.

(b) $\operatorname{sign}\left(T_{r}^{*}\right)=\operatorname{sign}\left(\alpha V_{T}-r V_{r}+V_{T r}\left(e^{r T^{*}}-1\right)\right)$, where $\alpha=T^{*}$ $e^{r T^{*}}-\frac{1}{r}\left(e^{r T^{*}}-1\right) \geqslant 0, V_{T} \geqslant 0$, and $V_{r} \leqslant 0$.

(c) $\operatorname{sign}\left(T_{S}^{*}\right)=\operatorname{sign}\left(e^{r T^{*}} q^{*}\left(T^{*}\right)-q^{*}(0)\right)$.

Proof. (a) By (11) we have $V^{\prime}(T)\left(e^{r T}-1\right)-r(V(T)-K)=0$ at $T=T^{*}$. Regarding $T^{*}$ as a function of $K$ and totally differentiating 
both sides with respect to $K$, we obtain

$r V^{\prime}\left(T^{*}\right) T_{K}^{*}-r=V^{\prime \prime}\left(T^{*}\right) T_{K}^{*}\left(e^{r T^{*}}-1\right)+V^{\prime}\left(T^{*}\right) e^{r T^{*}} r T_{K}^{*}$,

which after some simplification yields

$T_{K}^{*}=\frac{r}{\left(1-e^{r T^{*}}\right)\left(r V^{\prime}\left(T^{*}\right)+V^{\prime \prime}\left(T^{*}\right)\right)}$.

The right-hand side is positive since $1-e^{r T^{*}}<0$, and $r V^{\prime}\left(T^{*}\right)+$ $V^{\prime \prime}\left(T^{*}\right)<0$ by (12). Hence, $T_{K}^{*}>0$.

(b) Since $V$ is now a function of $T$ and $r$, we use the notation $V_{T}$ and $V_{T T}$ instead of $V^{\prime}$ and $V^{\prime \prime}$. Differentiating the equilibrium condition (11) with respect to $r$ and simplifying yields

$$
\begin{aligned}
T_{r}^{*}\left[\left(1-e^{r T^{*}}\right)\left(r V_{T}+V_{T T}\right)\right]= & V_{T r}\left(e^{r T^{*}}-1\right) \\
& +T^{*} V_{T} e^{r T^{*}}-r V_{r}+K-V,
\end{aligned}
$$

hence by substituting for $K-V$ using (11) again, and by (12), we have

$$
\begin{aligned}
& \operatorname{sign}\left(T_{r}^{*}\right) \\
& \quad=\operatorname{sign}\left(\left(T^{*} e^{r T^{*}}-\frac{1}{r}\left(e^{r T^{*}}-1\right)\right) V_{T}-r V_{r}+V_{T r}\left(e^{r T^{*}}-1\right)\right) .
\end{aligned}
$$

The coefficient $\alpha=T^{*} e^{r T^{*}}-\frac{1}{r}\left(e^{r T^{*}}-1\right)$ of $V_{T}$ at the right hand side of (16) is positive for $T^{*}>0$ since it is zero for $T^{*}=0$ and has a positive derivative with respect to $T^{*}$. From (11), it follows that $V_{T} \geqslant 0$.

By differentiating the expression $V=\int_{0}^{T} e^{-r t} R\left(q^{T}(t)\right) d t$ with respect to $r$, we obtain

$V_{r}=\int_{0}^{T}-t e^{-r t} R\left(q^{T}(t)\right) d t+\int_{0}^{T} e^{-r t} R^{\prime}\left(q^{T}(t)\right) \frac{\partial q^{T}(t)}{\partial r} d t$.

The second integral can be written as $c^{T} \int_{0}^{T}\left(\partial q^{T}(t) / \partial r\right) d t$, and this is equal to zero since $\int_{0}^{T}\left(\partial q^{T}(t) / \partial r\right) d t=\partial\left(\int_{0}^{T} q^{T}(t) d t\right) / \partial r=$ $\partial S / \partial r$

$=0$. Hence, $V_{r}=\int_{0}^{T}-t e^{-r t} R\left(q^{T}(t)\right) d t \leqslant 0$.

(c) We start again from (11) but now regard $V$ as a function of both $S$ and $T$, and $T=T^{*}$ as a function of $S$. By totally differentiating (11) with respect to $S$ and for briefness again suppressing arguments of functions we obtain

$r\left(V_{S}+V_{T} T_{S}^{*}\right)=\left(V_{T S}+V_{T T} T_{S}^{*}\right)\left(e^{r T^{*}}-1\right)+V_{T} e^{r T^{*}} r T_{S}^{*}$

which simplifies to

$T_{S}^{*}\left[\left(e^{r T^{*}}-1\right)\left(-r V_{T}-V_{T T}\right)\right]=\left(e^{r T^{*}}-1\right) V_{T S}-r V_{S}$.

Since $r V_{T}+V_{T T} \leqslant 0$ by (9), the sign of $T_{S}^{*}$ is equal to the sign of the right-hand side of (17). We continue by establishing expressions for $V_{T S}$ and $V_{S}$.

Let $q=q^{T^{*}}$ be the optimal path with associated $c=c^{T^{*}}$, i.e., $\int_{0}^{T^{*}} q(t) d t=S$ and $R^{\prime}(q(t))=c e^{r t}$ for all $0 \leqslant t \leqslant T^{*}$. Then, $\int_{0}^{T^{*}}(\partial q(t) / \partial S) d t=1$ and thus

$$
\begin{aligned}
V_{S} & =\frac{\partial}{\partial S}\left(\int_{0}^{T^{*}} e^{-r t} R(q(t)) d t\right)=\int_{0}^{T^{*}} e^{-r t} R^{\prime}(q(t)) \frac{\partial q(t)}{\partial S} d t \\
& =\int_{0}^{T^{*}} e^{-r t} e^{r t} c \frac{\partial q(t)}{\partial S} d t=c \cdot 1=c .
\end{aligned}
$$

By using (7), we obtain for the partial derivative of $V_{T}$ with respect to $S$ :

$$
\begin{aligned}
V_{T S} & =\frac{\partial}{\partial S}\left(e^{-r T^{*}} R\left(q\left(T^{*}\right)\right)-c q\left(T^{*}\right)\right) \\
& =e^{-r T^{*}} R^{\prime}\left(q\left(T^{*}\right)\right) \frac{\partial q\left(T^{*}\right)}{\partial S}-\frac{\partial c}{\partial S} q\left(T^{*}\right)-c \frac{\partial q\left(T^{*}\right)}{\partial S}=-\frac{\partial c}{\partial S} q\left(T^{*}\right) .
\end{aligned}
$$

Altogether we have

$\operatorname{sign}\left(T_{S}^{*}\right)=\operatorname{sign}\left(\left(1-e^{r T^{*}}\right) \frac{\partial c}{\partial S} q\left(T^{*}\right)-r c\right)$.

In order to obtain an expression for $\partial c / \partial S$, we write $P$ for $\left(R^{\prime}\right)^{-1}$. Then, $P$ is differentiable and we can write $\int_{0}^{T^{*}} q(t) d t=S$ as $\int_{0}^{T^{*}} P\left(c e^{r t}\right) d t=S$. Differentiating both sides with respect to $S$ (keeping $T^{*}$ fixed), we obtain

$$
\begin{aligned}
1 & =\int_{0}^{T^{*}} P^{\prime}\left(c e^{r t}\right) e^{r t} \frac{\partial c}{\partial S} d t=\frac{\partial c}{\partial S}\left(\left.\frac{1}{c r} P\left(c e^{r t}\right)\right|_{0} ^{T^{*}}\right) \\
& =\frac{\partial c}{\partial S} \frac{1}{c r}\left(P\left(c e^{r T^{*}}\right)-P\left(c e^{r 0}\right)\right)=\frac{1}{c r} \frac{\partial c}{\partial S}\left(q\left(T^{*}\right)-q(0)\right)
\end{aligned}
$$

hence

$\frac{\partial c}{\partial S}=\frac{c r}{q\left(T^{*}\right)-q(0)}$.

Hence, with (18), sign $\left(T_{S}^{*}\right)=\operatorname{sign}\left(e^{r T^{*}} q^{*}\left(T^{*}\right)-q^{*}(0)\right)$.

The optimal time between order moments, $T^{*}$, reflects the tradeoff between total discounted cost of buying new batches and total discounted sales revenue. If $K$ increases, then the total discounted cost increases, which can be offset by decreasing the number of order moments, i.e., increasing $T^{*}$. This provides the intuition for result (a).

The impact on $T^{*}$ from a change in $r$ is less clear, since an increase in $r$ decreases both discounted sales revenue and discounted cost of buying new batches. To offset the first effect, the seller might want to speed up sales and thus to decrease $T^{*}$, but this has the effect of increasing discounted buying cost. Indeed, we were not able to determine the sign of $T_{r}^{*}$ in general. In Section 4.2, we assume that the revenue function is based on linear demand; in that case, we find that $T_{r}^{*}>0$.

The intuition for a positive effect of $S$ on $T^{*}$ might be that a higher batch size makes it possible to take more time to sell the whole batch, thereby decreasing total discounted buying cost. This intuition, however, is misleading. For the linear case in Section 4.2, we find that the effect is ambiguous.

\subsection{Linear demand functions}

We consider the case where demand functions are linear. In this case, the inverse demand function is given by $\max \{a-b x, 0\}$ for some parameters $a, b>0$. Since we are free to use units for quantities and prices, without loss of generality, we can study the case where $a=b=1$, which results in the revenue function $R(x)=x(1-x)$ for $x \in[0,1]$ and $R(x)=0$ for $x>1$. Under this assumption, we have the following result concerning the optimal time between order moments.

Proposition 4.2. The optimal time between order moments $T^{*}$ satisfies the equation

$K-\frac{1}{2}\left(T^{*}-2 S\right)+\frac{r}{4} \frac{e^{r T^{*}}+1}{e^{r T^{*}}-1}\left(T^{*}-2 S\right)^{2}=0$.

Proof. Since the monopoly quantity $q^{\mathrm{m}}$ is equal to $1 / 2$, the time $T^{\mathrm{m}}$ needed to sell $S$ at this rate is equal to $2 S$. Then, (3) and (4) imply, for $T \in[2 S, \widehat{T}]$,

$S=\frac{1}{2}\left(T-\frac{1}{r} c^{T} e^{r T}+\frac{1}{r} c^{T}\right)$,

yielding

$c^{T}=\frac{r(T-2 S)}{e^{r T}-1}$ and $q^{T}(t)=\frac{1}{2}\left(1-\frac{e^{r t} r(T-2 S)}{e^{r T}-1}\right)$ for $t \in[0, T]$. 
The upper bound $\widehat{T}$ can be found by solving $q^{T}(T)=0$, which implies that $\widehat{T}$ is the solution of the equation $1-e^{-r T}=r(T-2 S)$. By writing $f(T)=1-e^{-r T}-r(T-2 S)$, we see that $f(2 S)>0$ and $f^{\prime}(T)=r\left(e^{-r T}-1\right) \leq r\left(e^{-2 r S}-1\right)<0$ for all $T \geq 2 S$; hence, this equation has a unique solution $\widehat{T}$. In particular, $\widehat{T}<2 S+1 / r$.

The optimal time between order moments, $T^{*}$, follows from (5). To evaluate the first term in (5), notice that $c^{T} q^{T}(T)=e^{-r T} R^{\prime}$ $\left(q^{T}(T)\right) q^{T}(T)=e^{-r T}\left(q^{T}(T)-2 q^{T}(T)^{2}\right)$, so

$$
\begin{aligned}
e^{-r T} R\left(q^{T}(T)\right)-c^{T} q^{T}(T) & =e^{-r T}\left(q^{T}(T)-q^{T}(T)^{2}\right)-c^{T} q^{T}(T) \\
& =e^{-r T} q^{T}(T)^{2} .
\end{aligned}
$$

To evaluate the last term in (5), we write

$e^{-r t} R\left(q^{T}(t)\right)=e^{-r t}\left(q^{T}(t)-q^{T}(t)^{2}\right)$,

where

$$
\begin{aligned}
e^{-r t} q^{T}(t) & =\frac{1}{2} e^{-r t}-\frac{1}{2} \frac{r(T-2 S)}{e^{r T}-1}, \\
e^{-r t} q^{T}(t)^{2} & =\frac{1}{4} e^{-r t}-\frac{1}{2} \frac{r(T-2 S)}{e^{r T}-1}+\frac{1}{4} \frac{e^{r t} r^{2}(T-2 S)^{2}}{\left(e^{r T}-1\right)^{2}},
\end{aligned}
$$

so

$e^{-r t}\left(q^{T}(t)-q^{T}(t)^{2}\right)=\frac{1}{4} e^{-r t}-\frac{1}{4} \frac{e^{r t} r^{2}(T-2 S)^{2}}{\left(e^{r T}-1\right)^{2}}$.

We find that

$$
\int_{0}^{T} e^{-r t} R\left(q^{T}(t)\right) d t=\frac{1}{4 r}\left(1-e^{-r T}\right)-\frac{1}{4} \frac{r(T-2 S)^{2}}{e^{r T}-1} .
$$

Substituting (20) and (21) in (5) and dividing by $r$, we find for this case of a linear demand function that (5) reduces to

$K-\frac{1}{2}\left(T^{*}-2 S\right)+\frac{r}{4} \frac{e^{r T^{*}}+1}{e^{r T^{*}}-1}\left(T^{*}-2 S\right)^{2}=0$

which is Eq. (19).

Eq. (19) implies immediately that $T^{*}>2(S+K)$. Since in the proof of Proposition 4.2 we derived that $\widehat{T}<2 S+1 / r$ and since $T^{*} \leq \widehat{T}$, we must have $2 K<1 / r$. In fact, from our assumption $K<w^{*}$ and Lemma 3.4, using (21) with $T=\widehat{T}$, it is easily seen that $4 K<1 / r$. We next show that the optimal time between order moments increases with the discount rate $r$.

Proposition 4.3. Let $\left(q^{*}, T^{*}\right)$ be the optimal strategy of (1) when the demand function is linear. Then, $T_{r}^{*}>0$.

Proof. We make use of the implicit function theorem, from which it follows that $T_{r}^{*}$ is equal to minus the ratio between the partial derivative of the left-hand side of Eq. (19) with respect to $r$ and the partial derivative with respect to $T^{*}$. In the proof of (a) of Proposition 4.1, it is shown that the latter derivative is negative. The partial derivative of the left-hand size of Eq. (19) with respect to $r$ equals $\left(T^{*}-2 S\right)^{2} / 4$ times

$$
\begin{aligned}
& \frac{\left(e^{r T^{*}}+r T^{*} e^{r T^{*}}+1\right)\left(e^{r T^{*}}-1\right)-\left(r e^{r T^{*}}+r\right)\left(e^{r T^{*}} T^{*}\right)}{\left(e^{r T^{*}}-1\right)^{2}} \\
& =\frac{e^{2 r T^{*}}-2 r T^{*} e^{r T^{*}}-1}{\left(e^{r T^{*}}-1\right)^{2}} .
\end{aligned}
$$

The sign of this expression is equal to the sign of the numerator. Then, $e^{2 r T^{*}}-2 r T^{*} e^{r T^{*}}-1=\left(e^{r T^{*}}-r T^{*}\right)^{2}-r^{2} T^{*^{2}}-1>\left(1+r T^{*}+\right.$ $\left.\frac{1}{2} r^{2} T^{*^{2}}-r T^{*}\right)^{2}-r^{2} T^{*^{2}}-1=\frac{1}{4} r^{4} T^{*^{4}}>0$, where the inequality follows from a second-order Taylor approximation to $e^{r T^{*}}$.

An increase in $r$ increases the benefits from postponing an order. For linear demand functions, this leads to an unambiguous positive effect of the discount rate on the optimal order time.

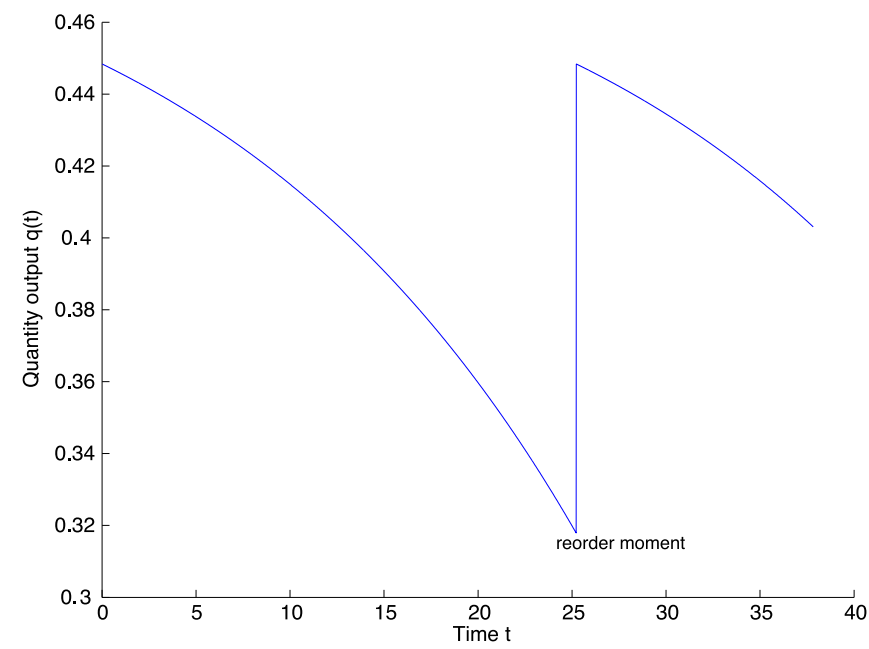

Fig. 1. The optimal sales path for $R(x)=x(1-x), S=10, r=0.05$, and $K=2$. It holds that $T^{\mathrm{m}}=20, \widehat{T}=36.83$, and $T^{*}=25.22$.

One may have the intuition that an increase in $S$ should also lead to an increase in the optimal order time, as one may guess that it takes longer to sell a bigger stock. This, however, is not always the case. Since it is shown in the proof of (a) of Proposition 4.1 that the partial derivative of (19) with respect to $T$ is negative, the sign of $T_{S}^{*}$ is equal to the sign of the partial derivative of (19) with respect to $S$. The latter derivative is equal to

$1-r \frac{e^{r T^{*}}+1}{e^{r T^{*}}-1}\left(T^{*}-2 S\right)$.

The sign of this derivative is positive if and only if

$T^{*}-2 S<\frac{1-e^{-r T^{*}}}{r\left(1+e^{-r T^{*}}\right)}$

Since

$\widehat{T}-2 S=\frac{1-e^{-r \widehat{T}}}{r}>\frac{1-e^{-r \widehat{T}}}{r\left(1+e^{-r \widehat{T}}\right)}$,

the sign of the derivative is negative when $T^{*}$ is sufficiently close to $\widehat{T}$.

For instance, when $S=4, r=0.05$, and $K=2$, we have that $\widehat{T}=21.00$ and $T^{*}=17.36$. When $S$ is increased to 4.1 , we find that $T^{*}=17.17$, so $T_{S}^{*}$ is approximately equal to -1.9 . In this example, the order costs are so high that the only way for the seller to make a positive profit is to choose a sales strategy that maximizes the revenues coming out of a single batch, i.e. is close to $q^{\widehat{T}}$, and the profits are barely positive. When $S$ increases, the seller can make a relatively much higher profit per batch, and by lowering the order time, he can increase the number of batches per time-period, which explains why $T_{S}^{*}$ can be negative in an optimal sales strategy. This case is not an artifact, but would be realistic for products with a low profit margin. Since $T^{*}>2(S+K)$, it is clear that for higher values of $S$, the sign of $T_{S}^{*}$ becomes positive.

In Fig. 1 we consider the case where $S=10, r=0.05$, and $K=2$ and plot the optimal sales path. In Table 1 , we take $K=2$ and display the value of $T^{*}$ for $S$ ranging from 3 to 10 and $r$ from 0.01 to 0.09 . The value $\infty$ is used when the order costs $K$ exceed the maximum discounted revenue $w^{*}$, which happens for low values of $S$ and high values of $r$. In these cases, the seller would not place new orders. We have shown in Proposition 4.3 that $T_{r}^{*}>0$. The values for $T^{*}$ in the columns of Table 1 are therefore increasing with $r$. We have argued that intuitively one would expect $T_{S}^{*}>0$, in particular for high values of $S$, but that $T_{S}^{*}<0$ may occur, in particular when profit margins are low. In Table 1, we have two instances of negative values of $T_{S}^{*}$ when $S=3$ and $r=0.01$ and 
Table 1

The value of $T^{*}$ for different values of $S$ and $r$ when $K=2$.

\begin{tabular}{lllllllll}
\hline$r$ & \multicolumn{1}{l}{ Batch size $S$} & \multicolumn{7}{l}{} \\
\cline { 2 - 8 } & 3 & 4 & 5 & 6 & 7 & 8 & 9 & 10 \\
\hline 0.01 & 18.21 & 16.03 & 16.68 & 18.01 & 19.61 & 21.34 & 23.15 & 25.01 \\
0.03 & $\infty$ & 16.35 & 16.83 & 18.11 & 19.69 & 21.42 & 23.22 & 25.08 \\
0.05 & $\infty$ & 17.36 & 17.19 & 18.35 & 19.88 & 21.58 & 23.37 & 25.22 \\
0.07 & $\infty$ & $\infty$ & 18.08 & 18.82 & 20.23 & 21.87 & 23.64 & 25.47 \\
0.09 & $\infty$ & $\infty$ & $\infty$ & 20.19 & 20.96 & 22.43 & 24.12 & 25.91 \\
\hline
\end{tabular}

when $S=4$ and $r=0.05$. In these cases, an increase in $S$ leads to a lower value of $T^{*}$.

\section{Concluding remarks}

The model in this paper can easily be extended to a model in which it takes a positive amount of time to deliver the good. This will have no major effect on the results.

We have seen that an increase in batch size does not necessarily result in an increase in the optimal order time. An interesting question for future research is the relation between batch size and optimal order time or, more generally, supply process.

We have already argued that our model fully accommodates holding costs that are related to the opportunity cost of capital invested in inventories. In addition to such opportunity costs, holding costs may include the costs of decay and costs related to space and handling of the product. This is one of the extensions that we leave as a future research direction.

\section{Acknowledgment}

We thank the editor and reviewers for their many constructive comments.

\section{References}

[1] A.H.J. van den Berg, P.J.J. Herings, H.J.M. Peters, The Economic Order Decision with Continuous Dynamic Pricing and Batch Supply, METEOR Research Memorandum 14/01, Maastricht, 2014. http://pub.maastrichtuniversity.nl/ e2a6b508-1342-4134-93bc-56fe21c6b75c.

[2] G.R. Bitran, R. Caldentey, An overview of pricing models for revenue management, Manuf. Serv. Oper. Manage. 5 (2003) 203-229.
[3] W. Chen, Q. Feng, S. Seshadri, Inventory-based dynamic pricing with costly price adjustment, Prod. Oper. Manage. 24 (2015) 732-749.

[4] X. Chen, P. Hu, Joint pricing and inventory management with deterministic demand and costly price adjustment, Oper. Res. Lett. 40 (2012) 385-389.

[5] X Chen, D. Simchi-Levi, Coordinating inventory control and pricing strategies with random demand and fixed ordering cost: The infinite horizon case, Math. Oper. Res. 29 (2004) 698-723.

[6] X. Chen, D. Simchi-Levi, Coordinating inventory control and pricing strategies: The continuous review model, Oper. Res. Lett. 34 (2006) 323-332.

[7] X. Chen, D. Simchi-Levi, Pricing and inventory management, in: Ö. Özer, R. Phillips (Eds.), The Oxford Handbook of Pricing Management, Oxford University Press, Oxford, 2012, pp. 784-822.

[8] S. Deng, C.A. Yano, Joint production and pricing decisions with setup costs and capacity constraints, Manage. Sci. 52 (2006) 741-756.

[9] W. Elmaghraby, P. Keskinocak, Dynamic pricing in the presence of inventory considerations: Research overview, current practices, and future directions, Manage. Sci. 49 (2003) 1287-1309.

[10] G. Feichtinger, R. Hartl, Optimal pricing and production in an inventory model Eur. J. Oper. Res. 19 (1985) 45-56.

[11] Q. Feng, Integrating dynamic pricing and replenishment decisions under supply capacity uncertainty, Manage. Sci. 56 (2010) 2154-2172.

[12] J. Geunes, Y. Merzifonluoğlu, H.E. Romeijn, Capacitated procurement planning with price-sensitive demand and general concave-revenue functions European J. Oper. Res. 194 (2009) 390-405.

[13] S.M. Gilbert, Coordination of pricing and multiple-period production across multiple constant priced goods, Manage. Sci. 46 (2000) 1602-1616.

[14] C. Holt, F. Modigliani, J. Muth, H. Simon, Planning Production, Inventories and Work Force, Prentice Hall, Englewood Cliffs, New Jersey, 1960.

[15] S. Jørgensen, Optimal production, purchasing and pricing: A differential game approach, European J. Oper. Res. 24 (1986) 64-76.

[16] S. Jørgensen, P.M. Kort, Optimal pricing and inventory policies: Centralized and decentralized decision making, European J. Oper. Res. 138 (2002) 578-600.

[17] D. Pekelman, Simultaneous price-production decisions, Oper. Res. 22 (1974) 788-794.

[18] A. Rajan, R. Steinberg, R. Steinberg, Dynamic pricing and ordering decisions by a monopolist, Manage. Sci. 38 (1992) 240-262. 